\title{
Protective Effect of Fruit Juices on Zn Nanoparticles Induced Toxicity ${ }^{\dagger}$
}

\author{
Ramya N. ${ }^{1}$, C. Valli Nachiyar ${ }^{1, *}$, Karthick Raja Namasivayam ${ }^{1}$ \\ 1 Department of Biotechnology, School of Bio and Chemical Engineering. Sathyabama Institute of Science and Technology, \\ Chennai 600119 Tamil Nadu, India \\ * Correspondence: vnachiyar@gmail.com; \\ $\dagger$ Presented at International Conference on Bioengineering for Health and Environment (ICBHE 2020)
}

Received: 5.07.2020; Revised: 10.07.2020; Accepted: 12.07.2020; Published: 15.07.2020

\begin{abstract}
Nanotoxicology refers to the study of the interaction of nanostructure with a biological system with an emphasis on elucidating the relationship between the physical and chemical properties of nanostructure with the induction of toxic biological responses. In this study, an attempt has been made to understand the protective effect of fruit juices on the reduction of $\mathrm{ZnO}$ nanoparticle-induced toxicity. Zinc oxide nanoparticles were synthesized by chemical reaction of zinc nitrate with sodium hydroxide as the reducer. Synthesized nanoparticles were characterized by suitable analytical techniques. UV-Vis spectroscopy study reveals the Plasmon absorption maxima at 200-600 nm, and Xray diffraction and Atomic Force Microscopic analyses revealed the highly stable nanoparticles. Nanoparticles coated fruit juices was confirmed by changes or shift in the absorption spectra. Phytotoxicity studies indicated that the fruit juices coated zinc oxide nanoparticles were not inducing any effect on seedling emergence and plant growth. Cytotoxicity studies using RAW 264.7 cell lines were done by MTT Assay, where the $\mathrm{IC}_{50}$ values.
\end{abstract}

Keywords: Nanostructure; fruit juices; cytotoxicity.

(c) 2020 by the authors. This article is an open-access article distributed under the terms and conditions of the Creative Commons Attribution (CC BY) license (https://creativecommons.org/licenses/by/4.0/).

\section{Funding}

This research received no external funding.

\section{Acknowledgments}

This research has no acknowledgment.

\section{Conflicts of Interest}

The authors declare no conflict of interest. 